\title{
Public perceptions, knowledge and awareness of cholesterol management in Singapore: a prospective pilot study
}

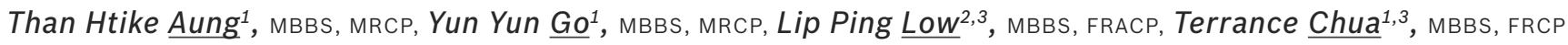

INTRODUCTION Hyperlipidaemia is a major risk factor for coronary artery disease (CAD). Its effective treatment has been shown to reduce the incidence of cardiovascular events, both in secondary and primary prevention. An essential component of risk factor management at the community level is public awareness and knowledge of treatment benefits. However, this data is limited in Singapore.

METHODS A cross-sectional survey questionnaire of public perception and knowledge on cholesterol treatment among adult Singaporeans aged 30-69 years was commissioned by the Singapore Heart Foundation and conducted by a professional market survey company. Regional quota sampling was performed to ensure that the sample was representative of the Singapore population. This was followed by random sampling of households and respondents.

RESULTS Of the 365 respondents, $40.9 \%$ were male, $70.3 \%$ were Chinese, $18.8 \%$ Malay and $10.9 \%$ Indian. The mean age was 47.5 years. Although $81.9 \%$ of respondents had medical check-ups involving blood tests, only $11.0 \%$ knew their actual cholesterol levels. A third of the respondents saw herbal medicine as healthier and safer than Western medication. More than $80 \%$ of respondents believed that diet and exercise were equally effective at lowering cholesterol as medication. About half of the respondents associated long-term use of statins with damage to the liver and kidney, while a third associated chronic statin use with the development of cancer.

CONCLUSION There are gaps in the level of public awareness and understanding of cholesterol treatment in Singapore. Common misconceptions should be addressed, as they could potentially impair effective management or treatment compliance.

Keywords: cholesterol, health knowledge, health surveys, hyperlipidaemia

Singapore Med J 2013; 54(1): 32-35

\section{INTRODUCTION}

Dyslipidaemia is one of the many well-established risk factors for cardiovascular diseases. High total cholesterol was ranked the second most prevalent cardiovascular risk factor among adult Singaporeans aged 18-69 years in the year 2010, (1) with a prevalence of $17.4 \%$, higher than diabetes mellitus, obesity and daily smoking. ${ }^{(2)}$ It is a modifiable cardiovascular risk factor with potential for the prevention of cardiovascular events. Indeed, the report from the National Cholesterol Education Programme showed that the decline in death rates from coronary artery disease was likely due to the improvement in modifiable risk factors in the general population. ${ }^{(3)}$

The general public's perception and attitude toward the management of cholesterol and other risk factors are critical in ensuring effective translation of evidence-based medicine into everyday practice. However, there is limited data on the general public's perception and awareness of this issue in Singapore. Anecdotally, as physicians, we often encounter concerns about the potential side effects of cholesterol treatment. Hence, this study was conducted to examine the level of public awareness and to identify areas of misconception with regard to cholesterol management.

\section{METHODS}

The study was commissioned by the Singapore Heart Foundation, which engaged a professional market survey company, Research Plus Pte Ltd, Singapore, to conduct a nationwide questionnaire survey. This study was supported by a grant from AstraZeneca Singapore Pte Ltd. The selection of subjects for the main sample involved quota sampling, followed by random sampling at two levels. Firstly, quota sampling across all five community development council districts was performed to ensure that the sample was representative of the Singapore population. Then, random sampling of households from each selected cluster was carried out. Among the residents of the household that were present at the time of the survey, the respondents were randomly selected using the Kisch Grid method. Door to door interviews were conducted from June 29, 2009 to August 3, 2009, on weekends from 10 am to $10 \mathrm{pm}$ and on weekdays from $6 \mathrm{pm}$ to $10 \mathrm{pm}$.

The total sample consisted of the main sample and a booster sample of respondents with high cholesterol levels. The main sample comprised 313 respondents, of which $17 \%$ had high cholesterol levels, while the booster sample comprised 52 respondents with high cholesterol levels, to ensure adequate sample size in this group of patients. In computing and presenting

\footnotetext{
${ }^{1}$ Department of Cardiology, National Heart Centre Singapore, ${ }^{2}$ Low Lip Ping Cardiology Clinic, Mount Elizabeth Medical Centre, ${ }^{3}$ Singapore Heart Foundation, Singapore Correspondence: A/Prof Terrance Siang Jin Chua, Deputy Director and Senior Consultant, Department of Cardiology, National Heart Centre Singapore, Mistri Wing, 17 Third Hospital Avenue, Singapore 168752. terrance.chua.s.j@nhcs.com.sg
} 
the results of the overall total study population, we corrected for the increased sampling of the high cholesterol group by weighting the results to match the distribution of the proportion of high cholesterol patients in the overall population. The eligibility criteria included adults aged 30-69 years who were either Singapore citizens or permanent residents. Respondents from market research, public relations, the media, pharmaceutical, medical or healthcare industry were excluded so as to avoid conflict of interest and potential bias.

\section{RESULTS}

A total of 365 subjects were interviewed, among whom 104 were reported to have dyslipidaemia that was diagnosed within the last five years. The demographic profile of the respondents involved in this study is as stated in Table I. The mean age of all the respondents in the study was 47.5 years, while the mean age of those with high cholesterol was 51.7 years. Of the $81.9 \%$ of respondents who had ever gone for medical check-ups that involved blood tests in the past, $70.6 \%$ had done so within the past one year. The mean age of respondents who had undergone medical check-ups was 48.5 years. The number of respondents who sought medical check-ups increased with age: $30-39$ years: $71.3 \%$; 40-49 years: $80.8 \%$; $50-59$ years: $86.8 \%$; and $60-69$ years: $91.3 \%$.

Unhealthy food or poor diet was identified as the top cause of high cholesterol. Some also attributed it to a lack of exercise and hereditary causes (Table II). Heart disease and stroke were seen to be related to high cholesterol level. In addition, high blood pressure was perceived to be a result or consequence of high cholesterol, albeit untrue (Table II). Only $11.0 \%$ of the total respondents knew their actual cholesterol levels, and this number was slightly higher among those with dyslipidaemia (17.3\%).

The respondents were asked to identify the statement(s) that they agreed with from a list (Table III). Several misconceptions on cholesterol and its treatment were noted in the survey. $64.9 \%$ of the respondents thought that people with high cholesterol usually have symptoms such as breathlessness or chest pain. Almost $40 \%$ of the respondents felt that one could stop the cholesterol medication once the cholesterol level was under control and expected the cholesterol level to still be within limits after the discontinuation of medication. More than half of the respondents thought that once initiated, it was unsafe to stop cholesterol medication. A third of the respondents believed that herbal medicine or supplements are superior to prescribed Western medication in terms of health benefits and safety profile. Further qualitative survey of the respondents who favoured herbal or traditional medicine found that some of the reasons given were that traditional medicine is more natural, has fewer side effects and addresses the root of the problem as compared to Western medication. A substantial number of respondents (87\%) deemed diet and exercise to be equally effective as medication for the control of dyslipidemia.

This study also revealed a few common misconceptions about the use of 3-hydroxy-3-methylglutaryl coenzyme A (HMG-CoA)
Table I. Demographic profile of the respondents.

\begin{tabular}{|c|c|c|}
\hline Characteristic & $\begin{array}{l}\text { All respondents }(\%) \\
\qquad(\mathrm{n}=365)\end{array}$ & $\begin{array}{l}\text { Respondents with } \\
\text { dyslipidaemia (\%) } \\
\text { (n=104) }\end{array}$ \\
\hline \multicolumn{3}{|l|}{ Age (yrs) } \\
\hline $30-39$ & 25.2 & 11.5 \\
\hline $40-49$ & 31.3 & 26.9 \\
\hline $50-59$ & 29.1 & 40.4 \\
\hline $60-69$ & 14.4 & 21.2 \\
\hline Male gender & 40.9 & 50.0 \\
\hline \multicolumn{3}{|l|}{ Race } \\
\hline Chinese & 70.3 & 73.1 \\
\hline Malay & 18.8 & 15.4 \\
\hline Indian & 10.9 & 11.5 \\
\hline \multicolumn{3}{|l|}{ Income (SGD) } \\
\hline None & 37.7 & 41.3 \\
\hline$<\$ 1,000$ & 11.5 & 8.7 \\
\hline$\$ 1,000-\$ 3,000$ & 29.4 & 22.1 \\
\hline$>\$ 3,000$ & 21.3 & 23.1 \\
\hline \multicolumn{3}{|l|}{ Educational level } \\
\hline Primary & 25.4 & 42.7 \\
\hline Secondary & 42.7 & 41.3 \\
\hline Tertiary & 31.9 & 28.8 \\
\hline \multicolumn{3}{|l|}{ Occupation } \\
\hline PMEBs & 27.0 & 29.8 \\
\hline Housewife & 25.1 & 22.1 \\
\hline Blue collar & 21.2 & 22.1 \\
\hline White collar & 13.4 & 11.5 \\
\hline Retired/Unemployed & 10.7 & 8.7 \\
\hline Others & 2.6 & 3.8 \\
\hline \multicolumn{3}{|l|}{ Housing type } \\
\hline $\mathrm{HDB}$ & 85.9 & 94.2 \\
\hline Landed property & 4.6 & 2.9 \\
\hline Condominium & 6.9 & 1.0 \\
\hline Shop house & 2.6 & 1.9 \\
\hline
\end{tabular}

*PMEB: professionals, managers, executives and business owners; HDB: Housing Development Board (government-subsidised housing)

Table II. Public's perception of the causes and effects of high cholesterol level.

\begin{tabular}{lcc}
\hline Question & $\begin{array}{c}\text { All respondents (\%) } \\
(\mathbf{n}=\mathbf{3 6 5})\end{array}$ & $\begin{array}{c}\text { Respondents with } \\
\text { dyslipidaemia (\%) } \\
(\mathbf{n}=\mathbf{1 0 4})\end{array}$ \\
& & \\
\hline $\begin{array}{l}\text { What are the main causes } \\
\text { of high cholesterol?* }\end{array}$ & & 87.5 \\
Unhealthy food/ poor diet & 88.0 & 10.6 \\
Lack of exercise & 7.2 & 5.8 \\
Hereditary & 3.2 & 2.9 \\
Sedentary lifestyle & 2.4 & 1.0 \\
Overeating & 2.4 & \\
What will happen when & & 34.6 \\
one has high cholesterol?* & & 24.0 \\
Heart disease & 36.7 & 11.5 \\
Stroke & 27.3 & 10.6 \\
High blood pressure & 20.1 & 3.8 \\
Blockage of vessels & 8.1 & \\
Fall sick & 4.8 & \\
\hline
\end{tabular}

*Multiple response question; percentages may not add up to $100 \%$.

reductase inhibitors, or statins. Almost half of the respondents thought that long-term use of statins would result in damage to the liver or kidney. More than a third of them associated long-term statin use with increased risk of cancer. There were numerically more respondents with tertiary education who associated 
Table III. Responses to questions assessing the respondents' knowledge of dyslipidaemia and statin use.

\begin{tabular}{|c|c|c|c|}
\hline \multicolumn{2}{|r|}{ Statements from questionnaire } & \multicolumn{2}{|c|}{ 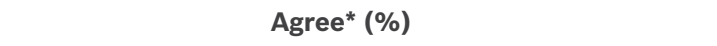 } \\
\hline & & $\begin{array}{l}\text { All respondents }(\%) \\
\quad(n=365)\end{array}$ & $\begin{array}{l}\text { Respondents with } \\
\text { dyslipidaemia (\%) }(n=104)\end{array}$ \\
\hline 1. & $\begin{array}{l}\text { People with high cholesterol usually have symptoms such as breathlessness } \\
\text { or chest pain. }\end{array}$ & 64.9 & 63.6 \\
\hline 2. & $\begin{array}{l}\text { Once cholesterol is under control, the person can stop taking medication and } \\
\text { it will continue to be under control. }\end{array}$ & 42.8 & 38.6 \\
\hline 3. & $\begin{array}{l}\text { Once a person is started on the cholesterol medication, it is not safe to stop } \\
\text { the medication. }\end{array}$ & 58.9 & 64.4 \\
\hline 4. & $\begin{array}{l}\text { To control cholesterol, it is healthier and safer to take herbal medicine or } \\
\text { supplement than taking prescribed Western medication. }\end{array}$ & 33.2 & 26.9 \\
\hline 5. & Diet and exercise are equally effective at lowering cholesterol as medication. & 87.8 & 85.6 \\
\hline 6. & $\begin{array}{l}\text { One of the side effects of the long-term use of medication for high cholesterol } \\
\text { such as statins is damage to the kidney. }\end{array}$ & 54.5 & 52.9 \\
\hline 7. & $\begin{array}{l}\text { One of the side effects of the long-term use of medication for high cholesterol } \\
\text { such as statins is damage to the liver. }\end{array}$ & 53.8 & 47.1 \\
\hline 8. & $\begin{array}{l}\text { Taking long-term cholesterol medication such as statins is associated with a } \\
\text { higher risk of cancer. }\end{array}$ & 37.7 & 34.6 \\
\hline
\end{tabular}

*Proportion of respondents who agreed with the inaccurate statements, expressed in percentage.

long-term statin use with kidney and liver damage compared to those with primary education $(61.4 \%$ vs. $42.5 \%, p=0.006$ and $55.4 \%$ vs. $44.4 \%, p=0.113$ for kidney and liver damage, respectively), but the latter was not statistically significant.

\section{DISCUSSION}

Despite the long-established evidence regarding the importance, safety and effectiveness of cholesterol treatment ${ }^{(4-6)}$ in the reduction of cardiovascular morbidity and mortality, our study revealed gaps in public awareness and understanding of hyperlipidaemia in Singapore. A considerable proportion of the general public $(86.0 \%)$ did not know their current cholesterol levels. This figure is higher than an earlier national survey by the American Heart Association, which reported that 50.8\% of adults aged 40 years and older did not know their own cholesterol level. ${ }^{(7)}$

In our study, heart disease and stroke were perceived to be the top two consequences of high cholesterol. However, one fifth of the respondents associated cholesterol with blood pressure. Similar misconceptions were also reported in another study, where some participants assumed that high cholesterol levels and high blood pressure cause each other and that the symptoms of the two conditions are the same. ${ }^{(8)}$ Although hyperlipidaemia does not directly produce symptoms, more than half the respondents linked high cholesterol with breathlessness or chest pain.

A third of the respondents felt that it was healthier and safer to take herbal medicine than prescribed Western medications. In Singapore, many people opt to seek traditional or herbal therapies to lower cholesterol level. Some of the reasons cited include personal preference, cultural beliefs, easy accessibility as these are largely over-the-counter items, or the patients could have experienced side effects from Western medications, e.g. myalgias.
However, the long-term effects of herbal medication have not been extensively studied.

The majority of our respondents $(87.8 \%)$ felt that diet and exercise are equally effective at lowering cholesterol as medication. On the contrary, medication is usually more effective at lowering cholesterol than lifestyle changes such as diet and exercise. ${ }^{(9)}$ However, the best result is achieved by combining diet and exercise with medication if a person's cholesterol level cannot be controlled by lifestyle changes alone. A nationwide study conducted in the United States from 1999 to 2006 involving 17,260 subjects - the National Health and Nutrition Examination Survey - revealed that compared to lifestyle changes alone, medications conferred an odds ratio of $2.68(95 \% \mathrm{Cl} 1.25-5.77$, $\mathrm{p}<0.001)$ at lowering blood cholesterol below $240 \mathrm{mg} / \mathrm{dL}$. In addition, those with both lifestyle changes and medication had the highest odds ratio of $4.10(95 \% \mathrm{Cl} 3.09-5.43, \mathrm{p}<0.01)$ for those with one or two lifestyle changes plus medication, and 4.27 $(95 \%$ Cl 2.96-6.17, p < 0.01) for those with three lifestyle changes plus medication. ${ }^{(9)}$ In addition, one common belief was that statins could be stopped once a target level of lipids was achieved, yet many also believed that statins could not be stopped once started.

More than half of the respondents believed that long-term use of statin would lead to liver and kidney damage, while 38\% of them associated its use with increased cancer risk. Contrary to these beliefs, systemic reviews on the adverse effects of statins showed that in randomised trials, there were fewer reports of hepatobiliary disorders and no excess of renal disease or proteinuria in patients allocated to statin compared to placebo. The notification rate of liver failure was one per million personyears of statin use. ${ }^{(10)}$ In addition, a report by the National Lipid Association revealed that cases of acute liver failure and acute or chronic kidney disease, after correcting for underreporting, were similar to their baseline rates in the general population. Hence, 
their link with statins could not be convincingly established. ${ }^{(11)}$ Regarding concerns for cancer risk, a previous large randomised study had found that there were no significant differences in the incidence of various cancers in patients receiving simvastatin compared to placebo during the follow-up period of 11 years. ${ }^{(6)}$

Paradoxically, a higher proportion of tertiary educated respondents appeared to believe that statins were associated with risks of cancer or liver disease, although this was not statistically significant in our small sample. We might speculate about the influence of misinformation that is widely available on the Internet, although this is conjectural. Nevertheless, previous studies have shown that the level of education has a significant impact on the public's knowledge and awareness on health matters. A recent study on the knowledge gaps and misconceptions concerning coronary heart disease (CHD) among South Asians in the United States found that individuals with lower education were associated with less knowledge, as well as the belief that CHD is not preventable. ${ }^{(12)}$

Our study has several limitations. The small sample size limits the generalisability of our findings. In addition, the validity and reliability of the questionnaire have not been tested or standardised from other studies. Due to the small sample size, we could not study the correlation between the characteristics of the respondents, for instance socioeconomic status, educational level and ethnicity, with their responses. Future study should focus on identifying the predictors of the public's responses and tailoring public education strategies effectively based on the profile of the target audiences.

In conclusion, there are gaps in public awareness and understanding of cholesterol management in Singapore. Our study offers insights into the magnitude of the problem and highlights the need for more effective measures to increase awareness on cardiovascular risk factor control. The results of this study also remind healthcare providers that listening to our patients and understanding their ideas, concerns and expectations are some of the keys to treatment success.

\section{REFERENCES}

1. Ministry of Health, Singapore. Singapore Health Facts 2010. Singapore, 2010.

2. Ministry of Health, Singapore. Disease Burden. In: Singapore Health Facts [online]. Available at: www.moh.gov.sg/content/moh_web/home/statistics/ Health_Facts_Singapore/Disease_Burden.html. Accessed August 15, 2012.

3. Cleeman JI, Lenfant C. The National Cholesterol Education Program: progress and prospects. JAMA 1998; 280:2099-104.

4. Ford I, Murray H, Packard CJ, et al. West of Scotland Coronary Prevention Study Group. Long-term follow-up of the West of Scotland Coronary Prevention Study. N Engl J Med 2007; 357:1477-86.

5. Downs JR, Clearfield M, Weis S, et al. Primary prevention of acute coronary events with lovastatin in men and women with average cholesterol levels: results of AFCAPS/TexCAPS. Air Force/Texas Coronary Atherosclerosis Prevention Study. JAMA 1998; 279:1615-22.

6. Heart Protection Study Collaborative Group, Bulbulia R, Bowman L, Wallendszus K, et al. Effects on 11-year mortality and morbidity of lowering LDL cholesterol with simvastatin for about 5 years in 20,536 highrisk individuals: a randomised controlled trial. Lancet 2011; 378:2013-20.

7. Nash IS, Mosca L, Blumenthal RS, et al. Contemporary awareness and understanding of cholesterol as a risk factor: results of an American Heart Association national survey. Arch Intern Med 2003; 163:1597-600.

8. Goldman RE, Parker DR, Eaton CB, et al. Patients' perceptions of cholesterol, cardiovascular disease risk, and risk communication strategies. Ann Fam Med 2006; 4:205-12.

9. Yoon SS, Carroll MD, Johnson CL, Gu Q. Cholesterol management in the United States: the national health and nutrition examination survey, 1999 to 2006. Ann Epidemiol 2011; 21:318-26.

10. Law M, Rudnicka AR. Statin safety: a systematic review. Am J Cardiol 2006; 97:52C-60C.

11. Guyton JR. Benefit versus risk in statin treatment. Am J Cardiol 2006; 97:95C-97C.

12. Kandula NR, Tirodkar MA, Lauderdale DS, et al. Knowledge gaps and misconceptions about coronary heart disease among US South Asians. Am J Prev Med 2010; 38:439-42.

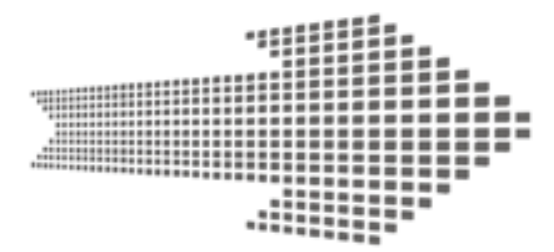

\section{Online Manuscript Submission www.editorialmanager.com/singaporemedj}

